\title{
KEPADATAN POPULASI KUPU-KUPU Troides helena L. DI AIR TERJUN TUNAN DESA TALAWAAN, MINAHASA UTARA DAN TAMANHUTANRAYAGUNUNG TUMPA, MANADO
}

\author{
Yuri El-Maurits Diang ${ }^{1)}$, Rooije R. H. Rumende ${ }^{\text {1) }}$, Hanny H. Pontororing 1) \\ ${ }^{1)}$ Program Studi Biologi, FMIPA Universitas Sam Ratulangi Manado \\ e-mail: yuriandre36@gmail.com; rooije.rumende@yahoo.com; hhpontororing@gmail.com
}

\begin{abstract}
ABSTRAK
Kepadatan populasi menunjukan besarnya populasi dalam satuan ruang.Umumnya dinyatakan sebagai jumlah individu atau biomasa persatuan luas atau volume. Penelitian ini bertujuan untuk menganalisis kepadatan populasi kupu-kupu Troides helena. Penelitian ini menggunakan metode survey berupa transek garis Penelitian ini dilakukan di dua tempat di Air Terjun Tunan Desa Talawaan Minahasa Utara dan Taman Hutan Raya Gunung Tumpa Manado. penelitian ini hanya dilakukan pada hutan sekunder yang sebagian besar lahannya telah dijadikan lahan pertanian. Kepadatan populasi tertinggi di daerah Air Terjun Tunan Desa Talawaan Minahasa Utara terdapat pada Transek $2\left(8 \mathrm{ekor} / \mathrm{km}^{2}\right)$. Kepadatan populasi terendah terdapat pada Transek 3 (3 ekor/ $\mathrm{km}^{2}$ ).Pada daerah Taman Hutan Raya Gunung Tumpa Manado kepadatan populasi tertinggi terdapat pada Transek $2\left(74 \mathrm{ekor} / \mathrm{km}^{2}\right)$.Kepadatan populasi terendah terdapat Transek 3 (14 ekor/ $\left./ \mathrm{km}^{2}\right)$.
\end{abstract}

Kata kunci :Kepadatan Populasi, Troides helena, Air Terjun Tunan, TAHURA Gunung Tumpa, Sulawesi Utara

\section{POPULATION DENSITY OFTroides helenaL. ON TUNAN WATERFALL IN TALAWAAN VILLAGE, NORTH MINAHASA AND FOREST PARK OF MOUNT TUMPA, MANADO.}

\begin{abstract}
Population density shows the size of the population in units of space. Generally expressed as the number of individuals or biomass in area or volume. This research aims to analyze the population density of Troides helena on Tunan Waterfall in Talawaan Village, North Minahasa and Forest Park of Mount Tumpa, manado. This study used a survey method in the form of the transect line.This research only in secondary forests is done on most of its land was made of agricultural land. The highest population density in the area Waterfall North Minahasa Talawaan Village Tunan found on Transect $2\left(8 \mathrm{tails} / \mathrm{km}^{2}\right)$. The low population density found in Transect 3 (3 tail $/ \mathrm{km}^{2}$ ). In the area Forest Park of Mount Tumpa, manado. Highest population density is found in the Transect $2\left(74 \mathrm{tail} / \mathrm{km}^{2}\right)$. The low population density there are Transect $3\left(14\right.$ tail $\left./ \mathrm{km}^{2}\right)$.
\end{abstract}

Keywords :Population Density, Troides helena, Tunan Waterfall, Forest Park of Mount Tumpa, North Sulawesi

\section{PENDAHULUAN}

Kupu-kupu Troides helena termasuk ke dalam suku Papilionidae dengan karakteristik memiliki tubuh yang besar dengan pola warna yang indah (Noerdjito dan Aswari, 2003). Troides helena merupakan kupu-kupu yang berukuran besar dengan rentang sayap 9,8-15 $\mathrm{cm}$ dan panjang sayap depan 6-9,5 cm. Kupu-kupu ini memiliki nama lain common birdwing, kupu- kupu raja helena atau kupu-kupu raja umum (Peggie, 2011). T. helena memiliki warna sayap yang menarik sehingga sering diambil dari alam untuk dijadikan koleksi dan diperdagangkan.Hal ini menjadi salah satu penyebab keberadaan kupu-kupu ini di alam semakin hari semakin berkurang. Penyebab lain semakin berkurangnya jumlah $T$. helena adalah keterbatasan jumlah pakan. Terdapat keterkaitan yang sangat erat antara kupu- 
kupu dengan tumbuhan untuk pakan larva, yang dikenal sebagai tumbuhan inang. Umumnya tiap jenis kupu-kupu memilih tumbuhan inang tertentu sebagai sumber makanan larva (Peggie, 2014).

Berdasarkan CITES (Convention on International Trade in Endangered Species of Wild Fauna and Flora) 20 spesies Troides termasuk dalam apendiks I dan apendik II. Kupu-kupu raja helena ini merupakan salah satu jenis kupu-kupu yang mendapatkan permintaan pasar yang tinggi (Peggie, 2011). Melalui uu no. 5 tahun 1990 tentang konservasi sumber daya alam hayati dan ekosistemnya dan Peraturan Pemerintah No. 7 Tahun 1999 tentang Pengawetan Jenis Tumbuhan dan Satwa, pemerintah Indonesia menetapkan perlindungan terhadap 12 spesies dari 15 spesies Troides yang ada di Indonesia (Peggie, 2011), termasuk didalamnya, $T$. helena.

Setiap spesies kupu-kupu memiliki hubungan yang spesifik dengan satu jenis tumbuhan (Achmad, 1998).Keberadaan spesies Troides di Sulawesi Utara dapat di jumpai di Cagar Alam Tangkoko Batuangus, Gunung Mahawu, Taman Nasional Nani Wartabone , Taman Hutan Raya Gunung Tumpa Manado, Kawasan Gunung Hutan Wiau Duasudara, Kawasan Air Terjun Tunan Desa Talawaan(Pontororing, 2017). Keberadaan T. helena di TAHURA Gunung Tumpa dan Air Terjun Tunan Desa Talawaan saat ini mengalami berbagai macam masalah yang sama sebagaimana yang terjadi di seluruh dunia yaitu pemanfaatan hutan oleh masyarakat untuk pembalakan komersial, kebakaran, pertanian dan proyek- proyek pembangunan, sehingga satwa khas sulawesi termasuk kupu-kupu T. helena yang sedang mengalami proses ancaman kelangkaan dan pemusnahan (Lee et al., 2001).
Berdasarkanuraian diatas untuk menunjang keberadaan kupu-kupu spesies Troides helena yang sudah terancam punah perlu diadakannya penelitian tentang kepadatan populasi T. helena L. di Air Terjun Tunan Desa Talawaan Minahasa Utara dan Taman Hutan Raya Gunung Tumpa Manado.

Penelitian ini bertujuan untuk menganalisiskepadatan populasi kupu-kupu T. helena di Air Terjun Tunan Talawaan Minahasa Utara dan Taman Hutan Raya Gunung Tumpa Manado.

\section{METODE PENELITIAN}

Metode yang digunakan dalam penelitian ini yaitu, survei dengan sampling berbentuk Transek garis untuk menentukan kepadatan populasi (densitas) kupu-kupu $T$. helena(Buckland et al.,1993). Penelitian ini dilakukan di dua tempat yaitu, di Air Terjun Tunan Desa Talawaan Minahasa Utara dan Taman Hutan Raya Gunung Tumpa Manado.Proses penelitian ini dimulai dengan penelitian pendahuluan yang dilakukan untuk menentukan lokasi yang akan dijadikan sebagai garis Transek. Garis Transek yang digunakan sebanyak tiga garis dengan panjang Transek $1000 \mathrm{~m}$. Luas area pengamatan sebelah kanan $100 \mathrm{~m}$ dan sebelah kiri $100 \mathrm{~m}$ dengan jarak antara Transek $500 \mathrm{~m}($ Gambar 8). Hal pertama yang dilakukan dalam pengumpulan data populasi di lapanganyaitu menentukan titik awal penjelajahan (titik $X$ ) dan titik akhir penjelajahan (titik Y)Setelah itupenjelajahan dimulai dari titik $\mathrm{X}$ dan berakhir di titik Y.Pengambilan data berdasarkan penglihatan langsung dengan asumsi setiap individu yang ditemukan berbeda dan dilakukan pengamatan selama 10 menit. (Mangangantung et al., 2015) (Gambar 1).

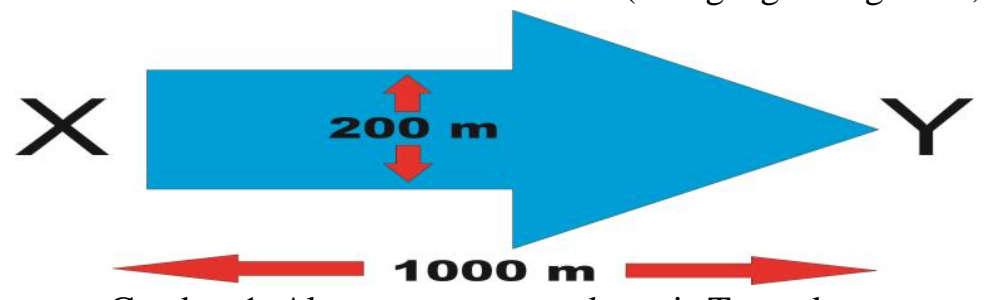

Gambar 1. Alur pengamatanpada garis Transek

Analisis data mengunakan rumus Ratarata hitung atau disingkat meanPenggunaan rata-rata hitung bersimbol ( $\bar{x}$ dibaca $\mathrm{X}$ bar).(Riduwan dan Akdon, 2013).dan rumus densitas yaitu, jumlah kontak dengan individu yang di temukan dalam 4 hari dibagi dengan panjang jalur pengamatan dikali lebar Transek (Mangangantung et al., 2015). 


$$
\frac{\bar{x}=\sum_{i=1}^{n} x i}{n}
$$

Dimana $: \bar{x}=$ rata-rata individu pada setiap Transek

$x i=$ jumlah individu pada setiap Transek

$\mathrm{n}=$ jumlah pengamatan pada setiap Transek

$$
\mathrm{D}=\frac{\sum x i}{L} \text { atau } \mathrm{D}=\frac{\sum x i / 4}{L}
$$

Dimana: $\mathrm{D}=$ densitas populasi $\left(\right.$ individu $\left./ \mathrm{m}^{2}\right)$

$x i=$ Jumlah individu (ekor)

$\mathrm{L}=$ luas Transek $\left(\mathrm{m}^{2}\right)$

\section{$4=4$ kali pengamatan pada setiap} Transek

\section{HASIL DAN PEMBAHASAN}

Kepadatan populasi Troides helena tertinggi terdapat pada Taman Hutan Raya Gunung Tumpa Manado Sulawesi Utara dengan jumlah individu tertinggi terdapat pada Transek 2 dan dan jumlah individu terendah terdapat pada Transek 3 ( Tabel 2).

Kepadatan populasi Troides helena terendah terdapat pada Air Terjun Tunan Talawaan Minahasa Utara dengan jumlah individu tertinggi terdapat pada Transek 2 dan dan jumlah individu terendah terdapat pada Transek3 (Tabel 1).

Tabel 1. Densitas Kupu-kupu T. Helena pada setiap Transek di Air Terjun Tunan Desa Talawaan Minahasa Utara

\begin{tabular}{ccccc}
\hline & & \multicolumn{3}{c}{ Transek (Individu) } \\
\cline { 3 - 5 } No & Hari & T1 & T2 & T3 \\
\hline 1 & Ke-1 & 2 & 4 & 0 \\
2 & Ke-2 & 0 & 1 & 1 \\
3 & Ke-3 & 3 & 1 & 0 \\
4 & Ke-4 & 0 & 0 & 1 \\
\hline \multicolumn{2}{c}{ Densitas (ekor/ km2) } & 1.25 & 14.75 & 0.5 \\
\hline Densitas Rata- rata (ekor/ km $\left.{ }^{2}\right)$ & 6 & 8 & 3 \\
\hline
\end{tabular}

Tabel 2. Densitas Kupu-kupu T. helena Pada Setiap Transek Di Taman Hutan Raya Gunung Tumpa

\begin{tabular}{ccccc}
\hline & & \multicolumn{3}{c}{ Transek ( Individu) } \\
\cline { 3 - 5 } No & Hari & T1 & T2 & T3 \\
\hline 1 & & 17 & 14 & 4 \\
2 & Ke-1 & 7 & 11 & 1 \\
3 & $\mathrm{Ke}-2$ & 10 & 27 & 3 \\
4 & $\mathrm{Ke}-3$ & 7 & 7 & 3 \\
\hline \multicolumn{2}{c}{ Ke-4 } & 10.25 & 14.75 & 2.75 \\
\hline \multicolumn{2}{c}{ Densitas (ekor/ km2) } & 51 & 74 & 14 \\
\hline
\end{tabular}


Kepadatan populasi tertinggi terdapat pada Transek 2 (8 ekor $\left./ \mathrm{km}^{2}\right)$, hal ini disebabkan, lokasinya yang berdekatan dengan aliran air terjun yang kaya akan mineral yang sangat dibutuhkan untuk keberlangsungan hidup kupu-kupu (Tabel 1). Rahayuningsih et al. (2012) menyatakan bahwa struktur vegetasi berupa pohon, tumbuhan berbunga, rumput dan semak serta lokasinya yang berdekatan dengan sumber air mampu menyediakan sumber pakan yang beragam memungkinkan kupu-kupu famili Papilionoidae memperoleh makanan serta tempat untuk berkembang biak. Menurut Glassberg (2001), sebagian besar jenis kupukupu, khususnya kupu-kupu jantan berkumpul di pasir atau tanah lembab, untuk menghisap garam mineral dan air. Kepadatan populasi terendah terdapat pada Transek 3 (3 ekor $/ \mathrm{km}^{2}$ ), hal ini disebabkan karena kurangnya vegetasi yang dijadikan sumber pakan kupu-kupu T. helena selain itu, tutupan kanopi yang begitu rapat sehingga menyebabkan cahaya matahari sulit menebus sehingga menyebabkan kurangnya intensitas cahaya. Hal ini sesuai dengan pendapat Koneri dan Saroyo (2012) yang menyatakan bahwa tersedianya sumber makanan bagi kupu- kupu, terdapatnya inang di lokasi tersebut serta intensitas cahaya yang mendukung kebutuhan hidup kupu- kupu memungkinkan organisme tersebut tidak perlu lagi mencari sumber makanan di tempat lain.

Kepadatan populasi tertinggi terdapat pada Transek 2 (74 ekor/ $\left.\mathrm{km}^{2}\right)$, hal ini disebabkan oleh tingginya keberagaman vegetasi yang dapat menjadi sumber pakan dan tempat berlindung bagi kupu-kupu T. helena (Tabel 2). hal sesuai dengan pernyataan Dennis et al. (2004) yang menyatakan bahwa banyaknya kupu- kupu pada suatu daerah dipengaruhi oleh penyebaran dan banyaknya tumbuhan pakan. Kepadatan populasi terendah terdapat pada Transek 3 (14 ekor $\left./ \mathrm{km}^{2}\right)$, hal ini disebabkan rendahnya vegetasi yang dapat menjadi sumber pakan dan tempat berlindung bagi kupu-kupu T. helena selain itu, transek 3 bukan merupakan jalur perlintasan kupu-kupu $T$. helena untuk mencari sumber pakan. Hal ini sesuai dengan pernyataan Rahayuningsih et al. (2012), vegetasi yang lebih beragam pada suatu habitat memiliki potensi ketersediaan pakan yang lebih banyak dibandingkan dengan habitat dengan yang kurang beragam.

Kepadatan populasi dan jumlah individu tertinggi terdapat pada daerah Taman Hutan Raya Gunung Tumpa yang disebabkan oleh tersedianya tumbuhan pakan yang lebih beragam. Kepadatan populasi dan jumlah individu terendah terdapat di Air Terjun Tunan Desa Talawaan Minahasa Utara yang disebakan oleh rendahnya sumber pakan kupu-kupu di daerah tersebut. Hal didukung oleh pendapat Rahayuningsih et al. (2012), rendahnya sumber pakan di area ini mengakibatkan beberapa jenis kupu-kupu melakukan migrasi ke area lain yang sumber pakannya lebih banyak.

\section{KESIMPULAN}

Kepadatan populasi tertinggi Troides helena di daerah Air Terjun Tunan Desa Talawaan Minahasa Utara terdapat pada Transek $2 \quad\left(8 \mathrm{ekor} / \mathrm{km}^{2}\right)$. Kepadatan populasi terendah $T$. helena terdapat pada Transek 3 (3 ekor $\left./ \mathrm{km}^{2}\right)$. Untuk di daerah Taman Hutan Raya Gunung Tumpa Manado kepadatan populasi tertinggi $T$. helena terdapat pada Transek 2 (74 ekor/ $\left./ \mathrm{km}^{2}\right)$. Kepadatan populasi terendah $T$. helena terdapat Transek $3\left(14\right.$ ekor $\left./ \mathrm{km}^{2}\right)$.

\section{SARAN}

Penelitian kepadatan populasi dan tumbuhan hinggap T. helena, perlu dilakukan di lokasi lain. Sehingga data di lokasi Air Terjun Tunan Minahasa Utara dan Taman Hutan Raya Gunung Tumpa Manado dapat dibandingkan dengan data yang diperoleh dari lokasi lain untuk memantau keberadaan kupukupu T. helena di Sulawesi Utara.

\section{DAFTAR PUSTAKA}

Achmad, A. 1998. Habitat dan pola Sebaran Kupu-kupu Jenis Komersil di Hutan Wisata Bantimurung Sulawesi Selatan.Majalah Ilmiah Flora dan Fauna, 8(8).Makassar: Fapertahut. Unhas.Ujung Pandang.

Buckland, S.T., D.R. Anderson, K.P. Burnham and J.L. Laake. 1993. Distance Sampling Estimating Abundance of Biological Populations. Chapman and Hall, London. 
Dennis R.L.H, J.G. Hodgson, R. Grenyer, T.G. Shreeve and D.B. Roy. 2004. Host plant and butterfly biology. Do host-plant strategies drive butterfly status?. J Ecological Entomology 29 (1): $12-26$

Glassberg, J. 2001. Butterflies Through Binocular the West: A Field Guid to the Butterflies of Western North America. Oxford University Press: New York.

Koneri, R dan S. Saroyo. 2012. Distribusi dan Keanekaragaman Kupu-Kupu (Lepidoptera) di Gunung Manado Tua, Kawasan TamanNasional Laut Bunaken, Sulawesi Utara. Jurnal Bumi Lestari 12 (2): 357-365.

Lee, R.J., J. Riley dan R. Merrill. 2001. Keanekaragaman Hayati dan Konservasi di Sulawesi Bagian Utara. WCS-IP dan NRM.

Mangangantung, B., D.Y. Katili, Saroyo dan P.V. Maabuat. 2015. Densitas dan Jenis Tumbuhan burung Rangkong (Rhyticeros cassidix) di Cagar Alam Tangkoko Batuangus. Jurnal Mipa Unsrat Online 4(1): 88-92

Noerdjito, W.A dan P. Aswari. 2003. Metode Survei dan Pemantauan Populasi Satwa. Seri Keempat KupuKupu Papilionidae. Bidang Zoologi, Pusat Penelitian Biologi-LIPI. Putra Nusantara. Bogor.

Peggie, D. 2011. Precious and Protected Indonesian Butterflies: Kupu-kupu Indonesia yang Bernilai dan Dilindungi. PT Binamitra Megawarna. Jakarta. Indonesia.

Peggie, D. 2014. Mengenal kupu-kupu.Pandu Aksara Publishing. Jakarta Indonesia

Pontororing, H.H. 2017. Konservasi kupukupu Troideshelena L. (LEPIDOPTERA: PAPILONIDAE) di Kawasan Hutan Lindung Wiau Duasudara Bitung dan Taman Hutan Raya Gunung Tumpa Manado Sulawesi Utara. [Disertasi]. Pascasarjana Universitas Sam Ratulangi Manado. Manado
Rahayuningsih, M., R. Oqtafiana dan B. Priyono. 2012. Keanekaragaman Jenis Kupu-kupu Superfamili Papilionodae di Dukuh Banyuwindu Desa Limbangan Kecamatan Limbangan Kabupaten Kendal.Jurnal MIPA 35(1): 58-64.

Riduwan dan Akdon. 2013. Rumus dan Data Analisis Statistika.Alfabeta.Jl. Gegerkalong Hilir 84. Bandung. 